\title{
Fused Heterocyclic Nitrogen Systems Containing Phosphorus Atom
}

\author{
DINA A. BAKHOTMAH and REDA MOHAMMADI ABDEL-RAHMAN \\ Department of Chemistry, Faculty of Science, King Abdul-Aziz University, Jeddah, Saudi Arabia. \\ *Corresponding author E-mail: dbakhotmah@kau,edu.sa \\ http://dx.doi.org/10.13005/ojc/310101
}

(Received: December 19, 2014; Accepted: January 21, 2015)

\begin{abstract}
Synthesis of fused heterocyclic nitrogen systems containing phosphorus atom via [1+4] Cyclocondensation, [3+2] cycloaddition, and 1,5-electrocyclization reactions are reviewed. Also, the modified synthesis methodology applicable to the fused phospha-five and six-membered rings.
\end{abstract}

Key words: Synthetic, Fused, Phosphaheteocyclization, phosphorus.

\section{INTRODUCTION}

Organophosphorus

compounds

Research has steadily flourished ${ }^{1}$ because these compounds have been reported to possess antiTMV activity ${ }^{2}$, herbicides ${ }^{3,4}$, insecticides ${ }^{5,6}$, molluscidal ${ }^{7}$, and some of here useful as strong basic proazaphosphatrans ${ }^{8}$, complexes ${ }^{9,10}$ also as superior catalyst of the protective silyation of wide variety of sterically hindered and deactivated alcohols ${ }^{11}$.

Fused and isolated heterocyclic nitrogen systems have been testified as anticancer ${ }^{12,13}$ and plant protection ${ }^{14}$ activities. In addition, phosphorus containing heterocyclic compounds exposed interesting biologically active ${ }^{15,16}$. Thus, in the present review an attempt has been made to highlight the synthesis and properties of fused heterocyclic systems containing phosphorus atom.

\section{Distribution}

The Synthetic strategy for new organophosphorus heterocyclic systems was analogous to the Krohnke's synthesis ${ }^{17}$ via [4+1] cyclo condensation, [3+2] cycloaddition ${ }^{18}$ and 1,5electrocyclization ${ }^{19}$. Bansal et $a^{20,21}$ and abdelRahman ${ }^{22}$ reported a brief reviews about the synthesis of indolizines and phosphaindolizines.

Synthesis via [4+1] cyclocondensation reactions are most important. Thus, synthesis of 2phosphoindolizines (3) was deduced from condensation of 1,2-dialkylpyridinium bromide (1) with $\mathrm{PCl}_{3}$ in presence of $\mathrm{Et}_{3} \mathrm{~N}$ via intermediate 2 [Scheme 1] $]^{23,24 .}$ 
<smiles>[R]Cc1ccc[n+](C([R])[R])c1C[R]</smiles>

Scheme 1: Synthesis of 2-phosphoindolizines<smiles>CCc1cccc[n+]1Cc1ccccc1</smiles>

4

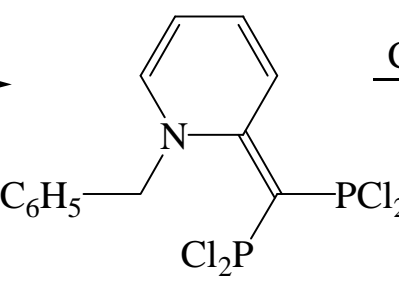

5<smiles>CCNC</smiles><smiles>CCCC</smiles>

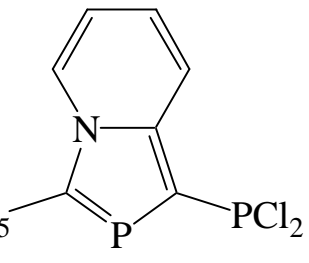

6

Scheme 2: Synthesis of 1-dichlorophosphino-2-phosphoindolizine

If $\mathrm{R}^{2}$ is methyl group, that reaction proceeds through the intermediate 5 to yield 1 dichlorophosphino-2-phosphoindolizine [Scheme 2] $]^{25}$.

Similarly, 1,3-azaphospholo[5,1b]thiazolines (7) and 1,3-azaphos-pholo[5,1b]benzothiazoles (8) were synthetic ${ }^{26}$.

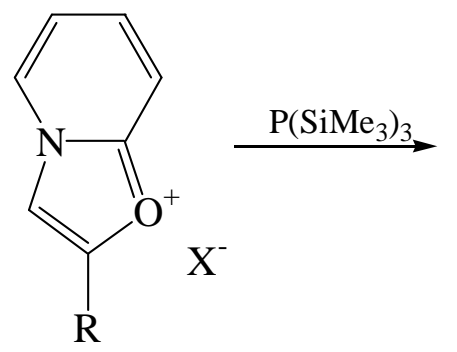

9

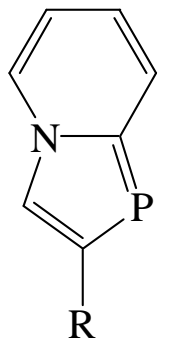

10

On the other hand, 1-phosphaindolizines (10) was obtained from condensation of 1,3oxazolo[3,2-a]pyridinium salt (9) with $\mathrm{P}\left(\mathrm{SiMe}_{3}\right)_{3}$ via exchange oxygen by phosphorus ${ }^{27}$.

A related condensation of 1-alkyl-2aminopyridinium salt (11) with $\mathrm{PCl}_{3}$ in presence of $\mathrm{Et}_{3} \mathrm{~N}$ led to the formation of 1-aza-2phosphindolizines (13) via the intermediate 12. [Scheme 3] $]^{28}$.

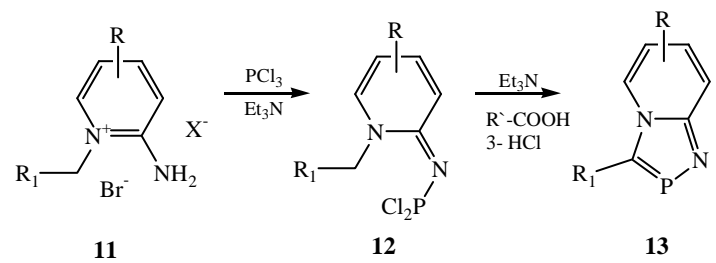

Scheme 3:

A large number of 3-aza-2phosphaindolizines (15) were prepared ${ }^{29}$ from condensation of 2-alkyl-1-aminopyridinium iodides (14) with $\mathrm{PCl}_{3}$ in presence of $\mathrm{Et}_{3} \mathrm{~N}$.

Also, 3-aza-phosphaindolizines (17) have been synthetic via O/P exchange of 1,3,4-oxadiazolo $[3,2-a]$ pyridinium salts (16) with $\mathrm{P}\left(\mathrm{SiMe}_{3}\right)_{3}{ }^{30}$.

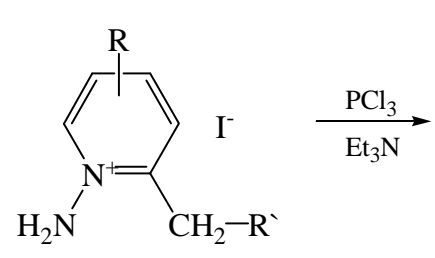

14<smiles>[R]c1nn2cccc([R])c2c1C</smiles>

15 


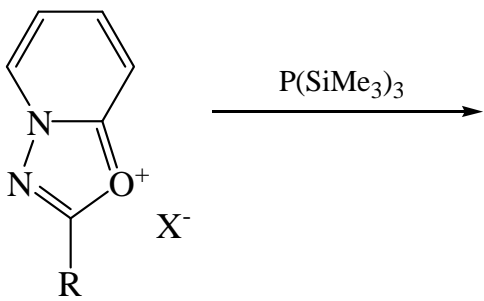

16

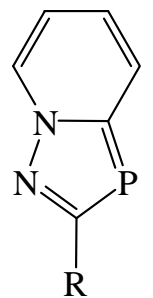

17

It is interesting that phospha-fused heterobicyclic as 1,3-diaza-2-phosphaindolizines (19) were obtained from cyclocondensation of 1,2diaminopyridinium iodides (18) with $\mathrm{P}\left(\mathrm{NMe}_{3}\right)_{3}$ in boiling dry benzene ${ }^{31}$.

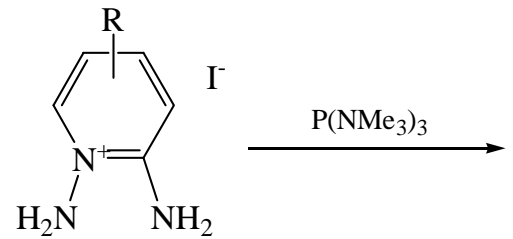

18<smiles>[R]c1ccn2npnc2c1</smiles>

19

On the other hand, [3+2] cycloaddition reactions were used tert-butylphospha acetylene 1,3-dipolarophile to condense with pyridinium (22) to give 2-phosphaindolizine (23) by boiling in dry toluene ${ }^{18}$.<smiles>CCOC(=O)c1nc(CC(C)C)c2ccccn12</smiles>

Karaghiosoff et $a^{32}$ reported the using of chloromethyl dichloro-phosphine $\left(\mathrm{ClCH}_{2} \mathrm{PCl}_{2}\right)$ as equivalent reagent yielding two-heterocyclic fused via C - P moiety by cyclocondensation with 2substituted azoles and azines through $[3+2]$ cyclocondensation reactions ${ }^{33}$.

Thus, 2-aminopyridine (20) condenses with $\left(\mathrm{ClCH}_{2} \mathrm{PCl}_{2}\right)$ in presence of $\mathrm{Et}_{3} \mathrm{~N}$ to produce 1,4,2-diazaphospholo[4,5-a]pyridine $(21)^{34}$.<smiles>Nc1c[R]ccn1</smiles>

20<smiles>[R]c1ccc2npcn2c1</smiles>

21
Azomethine ylides and azomethine imines incorporate that structure of 1,3-dipolar moiety bonded directly to an olefinic or acetylenic bond possesses 1,5-dipolar structure and have been utilized for the synthesis of five-membered heterocycles ${ }^{19,35}$

Thus, disproportionation of $N$-pyridinium dichlorophosphonium-methylides (24) would generate the bis-( $N$-pyridiniumylidyl) phosphonium chloride (25) which on disproportionation via 1,5electrocyclization by loss the pyridinium hydrochloride to yield 2-phosphaindolizine (26) $[\text { Scheme } 4]^{36}$.<smiles>[R]C([R7])([Ge])[n+]1ccccc1</smiles>

24

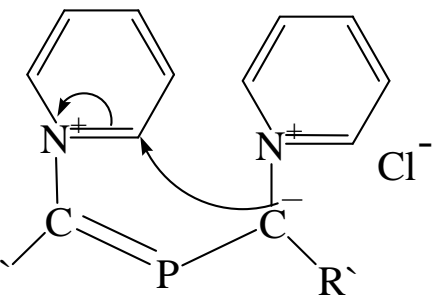

25

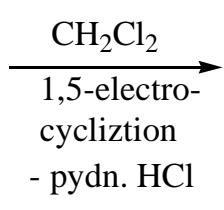

- pydn. $\mathrm{HCl}$<smiles></smiles>

26

\section{Scheme 4:Synthesis of 2-phosphaindolizine}

Abdel-Rahman ${ }^{22}$, reported the synthesis of new phosphaheterobi-cyclic system containing 1,2,4-triazine moiety via heterocyclizationa, this in cloud a novel synthesis of fluorine bearing 5- phospha-1,2,4-triazin-3-thiones and 5-phospha1,2,4-triazepin-3-thione.

Thus, a facile synthesis of fused 
phosphaheterobi-cyclic nitrogen system containing 1,2,4-triazine moiety was describe earlier. The treatment $\mathrm{N}$-substituted thiosemicarbazides ${ }^{37}$ (27) with diethyl benzoyl phosphate and/or diphenyl(2,4,6-trimethyl benzoyl) phosphine oxide in boiling dry toluene or $\mathrm{THF}^{38}$ afforded 4,5,6-
trisubstitued-5-phospha-1,2,4-triazin-3(2H)thiones (28 \& 29) respectively. Refluxing both the compounds 28 and 29 with trifluoroacetic anhydride yielded ${ }^{39}$ the full fluorinated phospha-1,2,4triazinethiones $\mathbf{3 0}$ and $\mathbf{3 1}$ respectively [Scheme 5$]^{22}$.

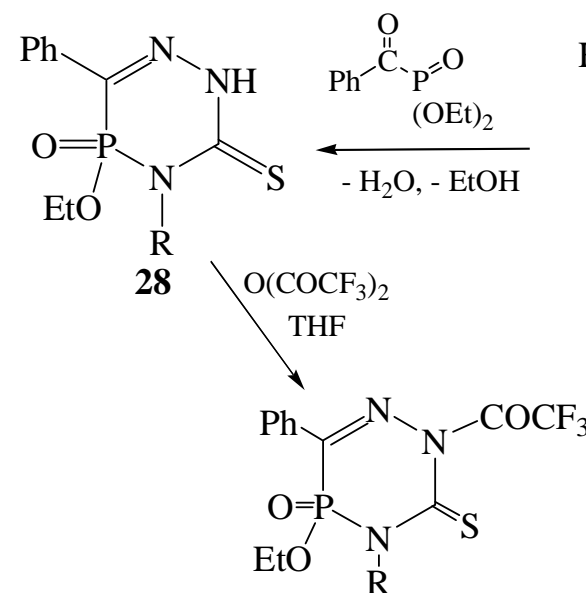

30<smiles>[R]NC(=S)NN</smiles>

27<smiles>[R]N1C(=S)NN=C([Al])P1(=O)c1ccccc1</smiles>

$\mathrm{THF}$<smiles>[R]N1C(=S)N(C(=O)C(F)(F)F)N=C([Al])P1(=O)c1ccc(F)cc1</smiles><smiles>Cc1nnc(-c2ccccc2)c(-c2ccccc2)n1</smiles>

, b,<smiles>Cc1ccc(F)c(F)c1F</smiles>

Scheme 5: Synthesis of fused phosphaheterobi-cyclic nitrogen system containing 1,2,4-triazine moiety

correspondingly, cyclocondensation of $N$ 4-substituted thiosemicarbazide (27) with acetonyltriphenylphosphonium chloride in boiling THF-DMF ${ }^{40}$ led to the direct formation of hexahydro4,7-disubstituted-5-triphenyl-5-phospha-1,2,4triazepin-3-(2H)thione $(32)^{22}$.
Presence of both $\mathrm{NH}$ and $\mathrm{CH}_{2}$ groups in the compound $\mathbf{3 2}$ was deduced from acylation and or condensation with trifluorobenzaldehyde ${ }^{40}$ to give the final products fluorine-bearing 1,2,4triazepin-3-thione derivative (34) [Scheme 6] ${ }^{22}$.

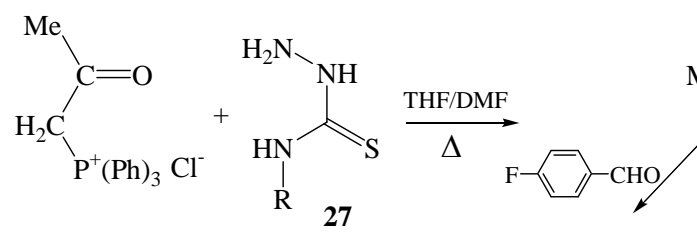

35<smiles>CC1=NNC(=S)N(P)P(=S)([InH])C1</smiles>

32

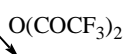

33

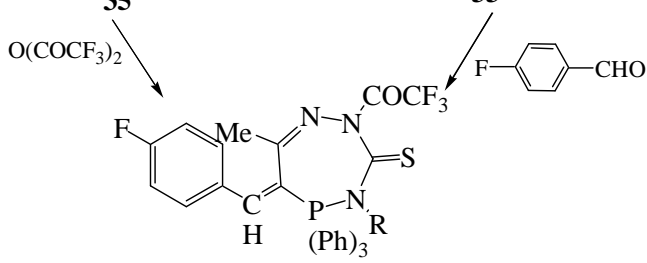

34

Scheme 6: Synthesis of fluorine-bearing 1,2,4-triazepin-3-thione derivative 
Regioselective iminophosphoranmediated annelation of a 1,3,4-thiadiazole ring into a 1,2,4-triazine ring was studied by Molina et $\mathrm{a}^{42}$. These studies based on aza-Wittig type reaction of iminophosphoane (37) followed by addition isothiocyanate-formed mesomeric or Zwitter ionic character $\mathbf{3 5}$ and $\mathbf{3 6}$. Treatment of compound $\mathbf{3 6}$ with primary aromatic amines afforded the Betaine 37 which under treatment with ethanol in the presence of tetrafluoro boric acid by stirring for 7 hours, resulted the 1,3-thiadiazetidines 38 via carbodiimide under goes [2+2] cycloaddition reaction [Scheme 7$]^{42}$.

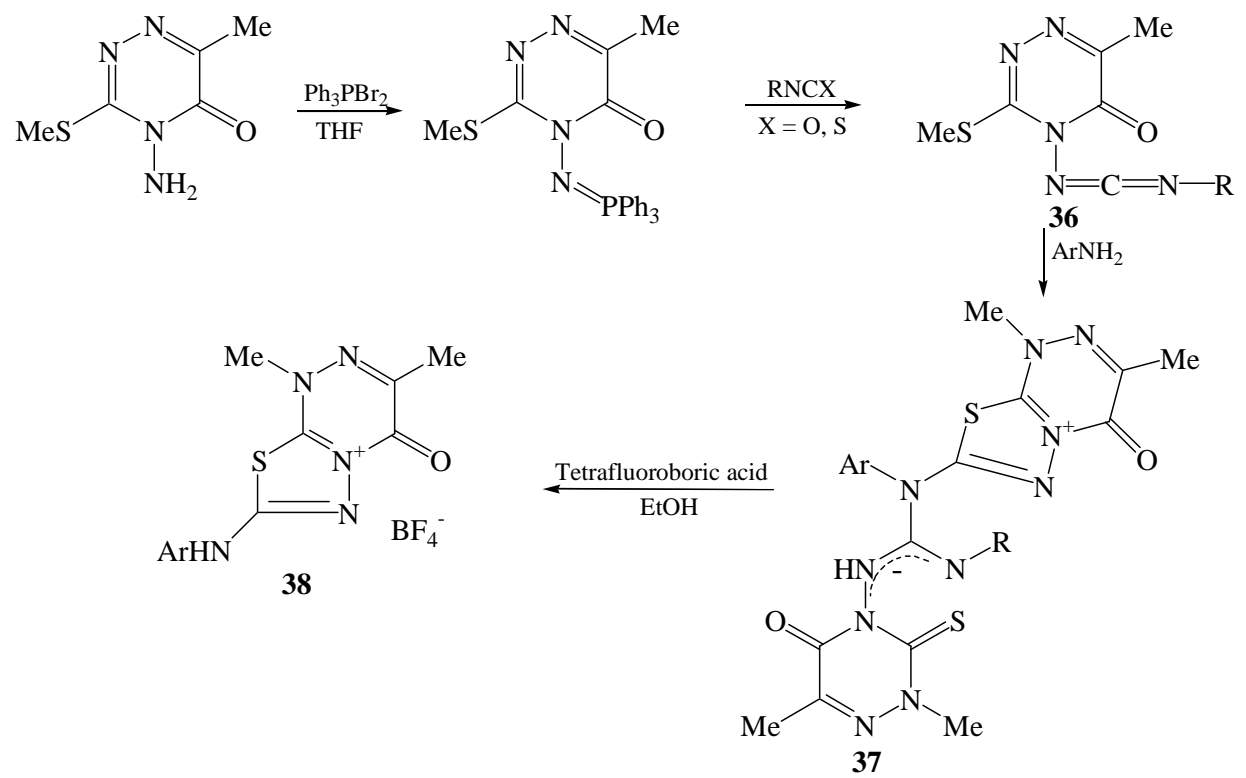

Scheme 7: Synthesis of 1,3-thiadiazetidines

From survey and various publications, it showed that a lethal work on the area of phospha1,2,4-triazines ${ }^{41-43}$. The first study between phosphorus and 5,6-diphenyl-1,2,4-triazin-3(2H) one (39) and some phosphorus reagents such as TPP, $\mathrm{P}(\mathrm{OR})_{3}$ and $\left(\mathrm{CH}_{2}\right)_{2} \mathrm{O}_{2} \mathrm{PZ}\left(\mathrm{Z}=\mathrm{Cl}\right.$, OMe, $\left.\mathrm{N}(\mathrm{Me})_{2}\right)$ were isolated phospha-heterocyclic system $\mathbf{4 0}$ obtained $^{43}$.<smiles>O=c1nc(-c2ccccc2)c(-c2ccccc2)n[nH]1</smiles>

39<smiles>[Z]P1OCCO1</smiles><smiles>O=C(O)C1CCCCC1=O</smiles>

$\mathrm{Ph}^{\prime}$<smiles>O=c1nc(-c2ccccc2)c(-c2ccccc2)nn1P1OCCO1</smiles>

40
The pesticides are a group of chemicals intended for perveting/destroying production, processing storage transportation and distribution of food. Thus, thiophosphate pesticides are the most effective insecticides and are used to control a wide variety of insect's pest as Parathion ${ }^{6}$ (41). Also the insecticide as Dimethaoate ${ }^{5}$ (42). 
<smiles>CC[PH](=S)Oc1ccc([N+](=O)[O-])cc1</smiles>

41

Several studies ${ }^{12,13,44}$ found that fused heterobicyclic nitrogen systems have a wide spectrum of medicinal and biological activities. Thus, treatment $^{22}$ of 3-amino-5,6-dimethyl-1,2,4-triazine<smiles>CNC(=O)CSP(OC)OC</smiles>

42

(43) with triphenylphosphine dibromide in toluene $e^{38}$ afforded compound 44 , while refluxing of 43 with $(\mathrm{EtO})_{3} \mathrm{P}=\mathrm{O}$ in dry toluene ${ }^{45}$ yielded compound 45 [Scheme 8] ${ }^{22}$.<smiles>Cc1nnc(N)nc1C</smiles>

43

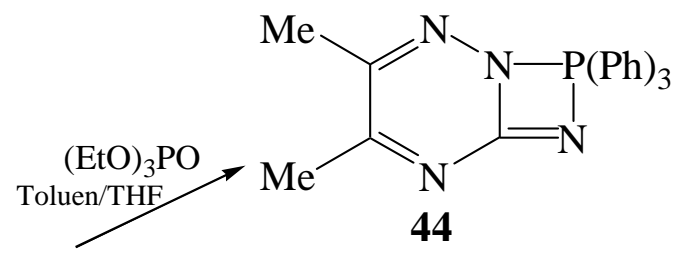<smiles></smiles>

Scheme 8: Synthesis of fused heterobicyclic nitrogen systems

In addition, condensation of 3 -aminotriazine 43 with aromatic aldehyde and $(p-$ $\left.\mathrm{ClC}_{6} \mathrm{H}_{4}\right)_{3} \mathrm{P}$ and/or acetophenone/ $\mathrm{ArPCl}_{2}$ in presence of dry toluene ${ }^{40,46}$-TEA led to the direct formation of phospha heterocyclic systems 46 and 47 respectively [Scheme 9$]^{23}$. Formation of compound $\mathbf{4 6}$ may be takes place as shown in Scheme $10^{47}$.

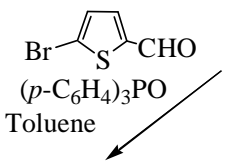<smiles></smiles><smiles>Cc1n[nH]c(=N)nc1C</smiles>

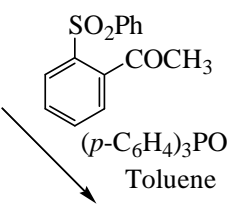<smiles>CC1=NC2=NC(C)(c3ccccc3S(=O)(=O)[O-])P(=O)(c3ccc(Cl)cc3)NN2N=C1C</smiles>

Scheme 9: Condensation of 3-amino-triazine 43 with aromatic aldehyde 
<smiles>Cc1nnc(N=CC(=O)C(C)C)nc1C</smiles>

Scheme 10: Formation of compound 46

In addition, the reaction of 3-amino-5,6dimethyl-1,2,4-triazine (43) with diethyl benzyl phosphonate and/or $\left(\mathrm{NEt}_{2}\right)_{3} \mathrm{P}^{+} \mathrm{Br}^{-}$in dry toluene produced the phospha heterocyclic systems $\mathbf{4 8}$ and 49 respectively [Scheme 11$]^{23}$.<smiles>CC1=NC2=NP(=O)(Cc3ccccc3)N2N=C1C</smiles>

48<smiles>CCOC(=O)c1ccccc1</smiles>

43<smiles>CCN(CC)P1(=O)N=C2N=C(C)C(C)=NN21</smiles>

49

\section{Scheme 11: Phospha heterocyclic systems}

On the other hand, 3-amino-6-methyl-5styryl-1,2,4-triazine (50) react with $\mathrm{CS}_{2}$ in alcoholic $\mathrm{KOH}$ to give (6-methyl-5-styryl-1,2,4-triazin-3yl)dithiocarbamic acid (51), which work as a building block for fused phospha-heterobicyclic systems 52-57 as bi-six-membered rings ${ }^{22}$. Thus, compound $\mathbf{5 1}$ on treatment with phosphorus reagents such as $(\mathrm{Ph})_{3} \mathrm{PBr}, \mathrm{P}\left(\mathrm{NR}_{2}\right)_{3}$ and $(\mathrm{MeO})_{3} \mathrm{P}=\mathrm{O}$ in refluxing toluene-TEA furnished 1,2,4-triazino[2,3-c][1,2,5,2]thiadiapho-sphorin-6thiones (52-54) respectively [Scheme 12] $]^{22}$.

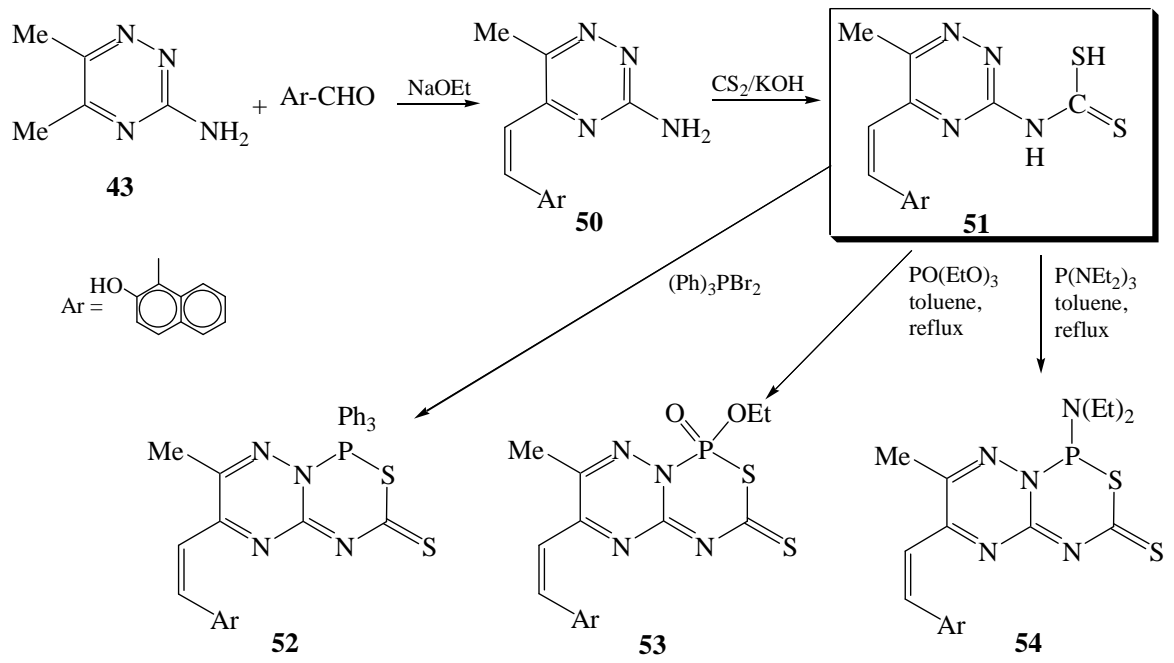

Scheme 12: Synthesis of 1,2,4-triazino[2,3-c][1,2,5,2]thiadiapho-sphorin-6-thiones 
The behavior of marcapto group in compound $\mathbf{5 1}$ towards halogenated phosphorus reagents to produce compounds $\mathbf{5 5 - 5 7}$ is similar to its reaction with various alkylating agents and or ketonic agents. It is worthy of mention that nucleophilic attack on $\mathrm{SH}$ is more than $\mathrm{NH}$ group by chlorinated phosphorus reagents ${ }^{48}$. Thus, refluxing compound $\mathbf{5 1}$ with $\mathrm{CNCH}_{2} \mathrm{P}(\mathrm{O})(\mathrm{OEt})_{2}$, $\mathrm{PhCH}_{2} \mathrm{P}(\mathrm{O})(\mathrm{OEt})_{2}$ and $\mathrm{Br} \mathrm{P}^{+}\left(\mathrm{NEt}_{2}\right)_{3}$ in THF-DMF furnished the target compounds 55-57 [Scheme $13]^{22}$.

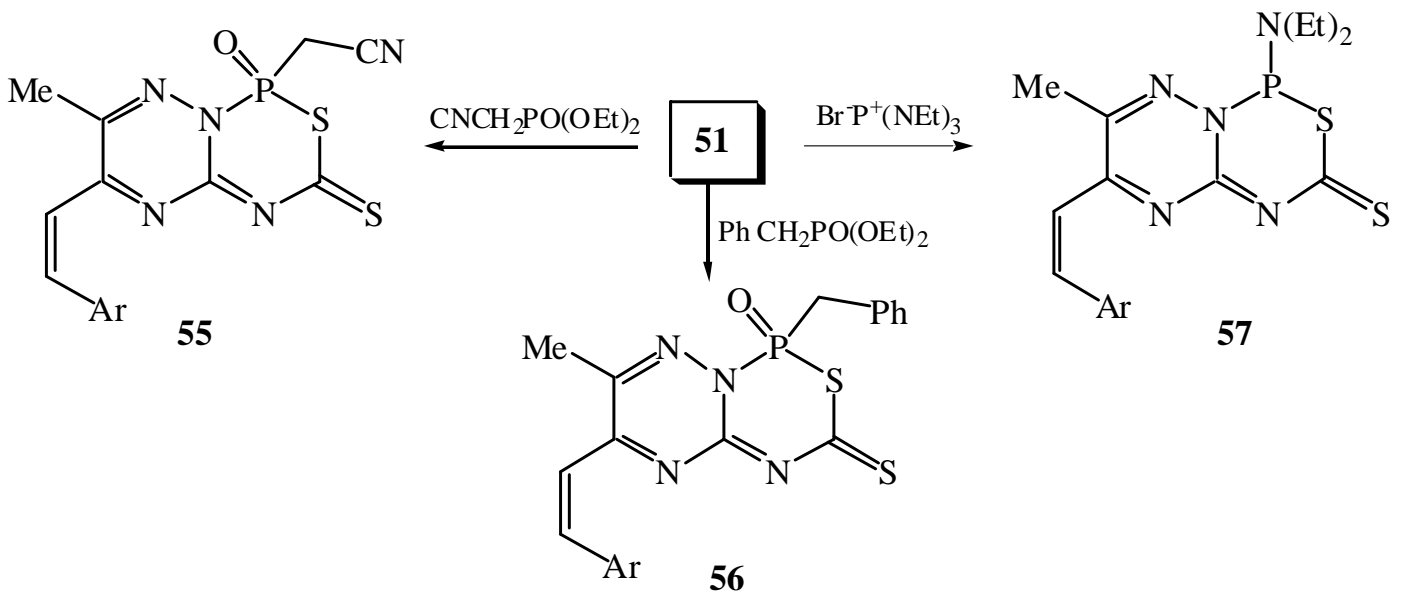

Scheme 13: Synthesis of some marcapto group compound

The tautomeric structures and proton mobility in position 3 and 2 of 1,2,4-triazines considered to be important in heterocyclization process with halogenated phosphorus reagents. ${ }^{22}$ Also, the reactivity structure relationship showed that phospha-1,2,4-triazine similar as Atranes which have unexpected properties ${ }^{49}$.
Ibrahim et $\mathrm{a} / \mathrm{I}^{50}$, reported the synthesis of novel 1,2-thiaphos-pholo[4,5- e][1,2,4]triazines (60) by treatment of 1,2,4-triazin-6-one (58) and or 1,2,4triazin-6-thione (59) with different percentage of Lawesson's reagent (LR) ${ }^{51}$ [Scheme 14].<smiles>COc1ccc(P2(=S)SC3=NNC(c4ccccc4)=NC3=C2[Se])cc1</smiles>

Scheme 14: Synthesis of novel 1,2-thiaphos-pholo[4,5- e][1,2,4]triazines

The molecular modifications of 1,2,4triazine rings by introducing organophosphorus functionalities might be expected to exhibit the potential activities depending on the position of the phosphoryl group to 1,2,4-triazine ring, AbdelRahman et $a^{6}$, studied synthesis of phosphorus containing fused and isolated heterobicyclic nitrogen systems via reaction of 5,6-bis(4- 
bromophenyl)-3-hydrazino-1,2,4-triazine (61) with some phosphorus reagents in non-polar solvent under various temperatures, the 6,7-diaryl-2,3dihy d ro-3, 3, 3-triphenyl-1,2, 4,triazaphospholino[4,5-b][1,2,4]triazine (62) was synthesized by stirring compound 61 with dibromotriphenylphosphorane in THF at room temperature for 24 hours [Scheme 15] $]^{6}$. Formation of 62 may be occurred via heterocyclization of the intermediate $N^{1}, N^{2}$-disubstituted hydrazine. The ${ }^{13} \mathrm{CNMR}$ spectrum of compound $\mathbf{6 2}$ showed signal at' $29.61 \mathrm{ppm}^{52}$.

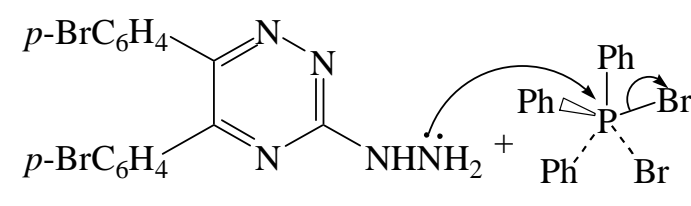

61<smiles>[Al]C1=NC2=NNP(c3ccccc3)(c3ccccc3)(c3ccccc3)N2N=C1[Al]</smiles>

62

\section{Scheme 15: Synthesis of 6,7-diaryl-2,3-dihydro-3,3,3-triphenyl $-1,2,4,-$ triazaphospholino[4,5-b][1,2,4]triazine}

Phosphorylation of 3-hydrazino-1,2,4triazine 61 via treatment with acetonyl triphenylphosphonium chloride under stirring in THF-piperidine for $24 \mathrm{~h}$, at room temperature furnished $N^{1}, N^{2}$-disubstituted hydrazine 63. Ring closure of 63 by heating above its melting point produced the heterobicyclic system 64 [Scheme $16]^{6}$. On the other hand, that reaction when carried out under refluxing, the isomeric structure 5,6-bisaryl-3-\{(3,3,3-triphenyl)-5-methyl-3,4-dihydro- $2 \mathrm{H}$ 1,2,3- $N^{5}$-diazaphosphol-2-yl\}-1,2,4-triazine (65) [Scheme 16] .

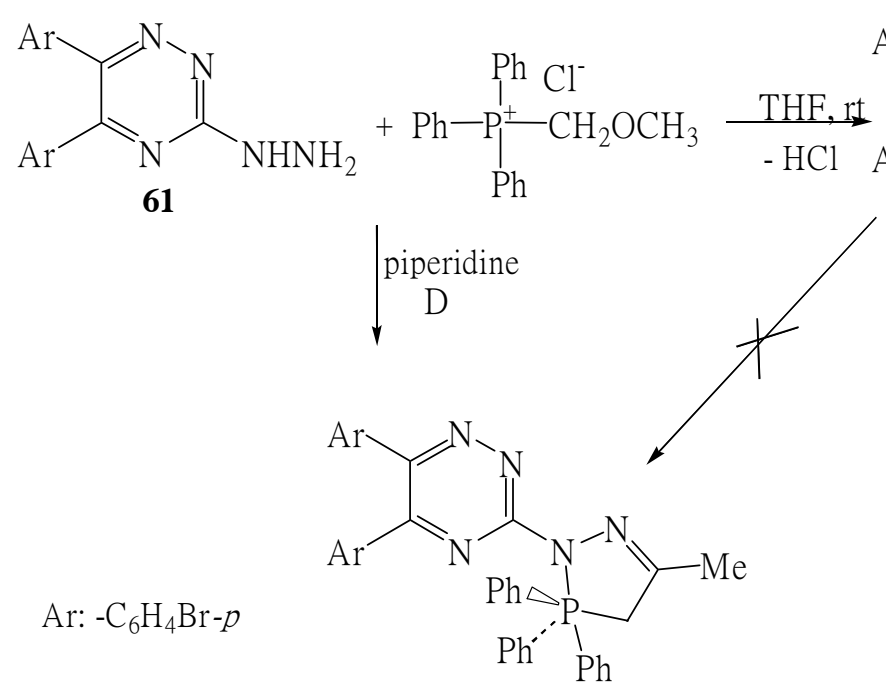

65<smiles>CC(=O)CP(NNc1nnc([Al])c([Al])n1)(c1ccccc1)(c1ccccc1)c1ccccc1</smiles><smiles>CC1=C[P+](c2ccccc2)(c2ccccc2)NN1c1nnc([Al])c([Al])n1</smiles>

64

\section{Scheme 16: Synthesis of some heterocyclic system}

The treatment of 3-hydrazinotriazine 61 with diethylphosphite and/or 2-chlorophenyl dichlorothiophosphate in THF/piperidine at room temperature produced the phosphonohydrazide 66 and phosphono-hydrzidothionic acid $\mathbf{6 7}$ respectively [Scheme 17], while the reactions under reflux afforded directly the 1,2,4,3triazaphospholo[4,5-b][1,2,4]triazines 68 and 69 respectively [Scheme 17]. 'HNMR spectra of 68 and 69 showed signals of $\mathrm{NH}$ protons at ' 10.92 and $10.34 \mathrm{ppm}$, respectively with respect to similar reported data ${ }^{53-55}$. 
Similarly, compound $\mathbf{7 0}$ isolated from treatment of $\mathbf{6 1}$ with diphenyl(2,4,6trimethylbenzoyl)phosphorus oxide by stirring with THF at room temperature while 7,8-bisaryl-4,4diphenyl-3-(2',4',6'-trimethyl-phenyl)-4H-451,2,4triazino[3,2-c][1,2,4,5]triaza- phosphinin-4-ol (71) was isolated under refluxing [Scheme 18] $]^{6}$.Due to driving force of $\mathrm{P}=\mathrm{O}$ bond is strong and phenyl groups are bad leaving groups, the nucleophilic attack of hydrazine moiety may be carried out at carbonyl group then $\mathrm{P}=\mathrm{O}$ group ${ }^{6}$.

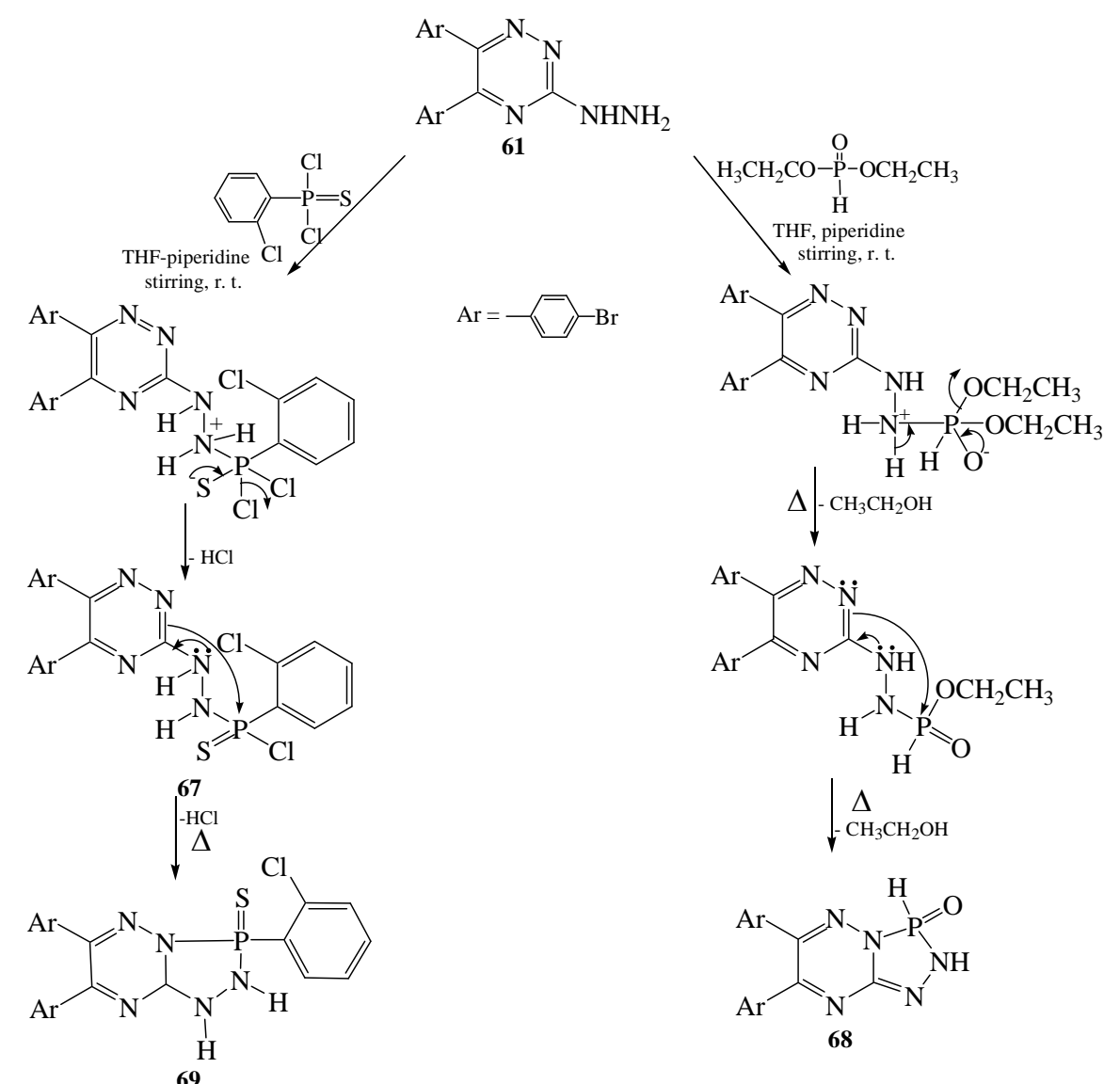

Scheme 17: Synthesis of 1,2,4,3-triazaphospholo[4,5-b][1,2,4]triazines 68 and 69

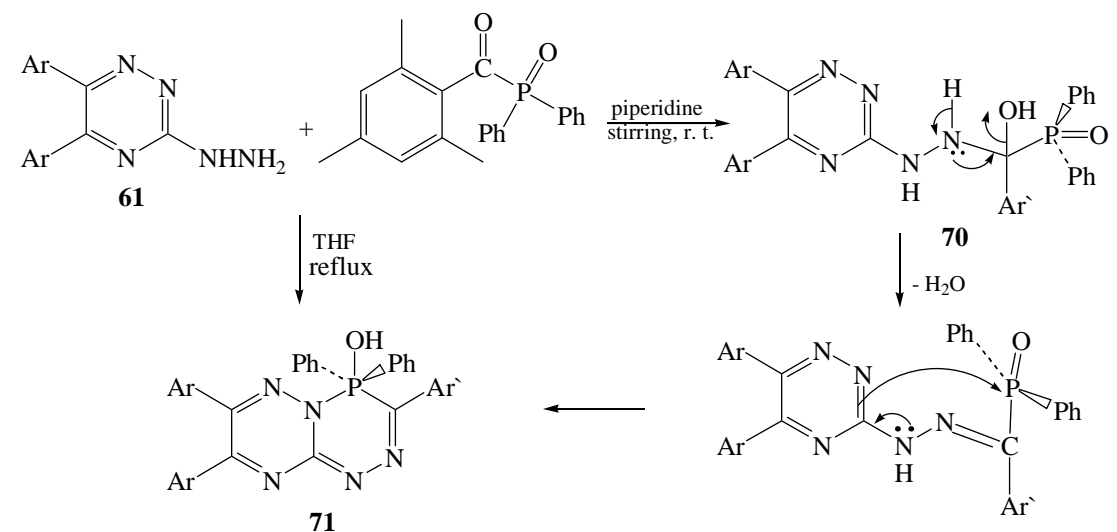

Scheme 18: Synthesis of compound 71 
Phosphorus compounds with a \pm -nitrogen or \pm -oxygen more often exhibited interesting biological properties ${ }^{56}$. Thus, introducing of P-C-O or P-C-N pattern into heterocyclic systems may be enhancing their biocidal effects. Thus, compounds 62-71 showed strong effects on the tested snails, which due to facile donation and back donation in d-orbital of phosphorus atom ${ }^{6}$.
Condensation of 4-oxo-4H-chromene-3carboxaldehyde (72) with phosphonic dihydrazide (1:1 by moles) when heated in boiling ethanol yielded the mono-hydrazone 73 . Addition of diethyl phosphite to the azomethine bond of monohydrazone 73 by heating at $80-100^{\circ} \mathrm{C}$ in TEA led to the direct formation of 3-(4-amino-5-ethoxy3,5-dioxido-1,2,4,3,5-triazadiphosphinan-6-yl)4Hchromen-4one(74) [Scheme 19] ${ }^{57,58}$.
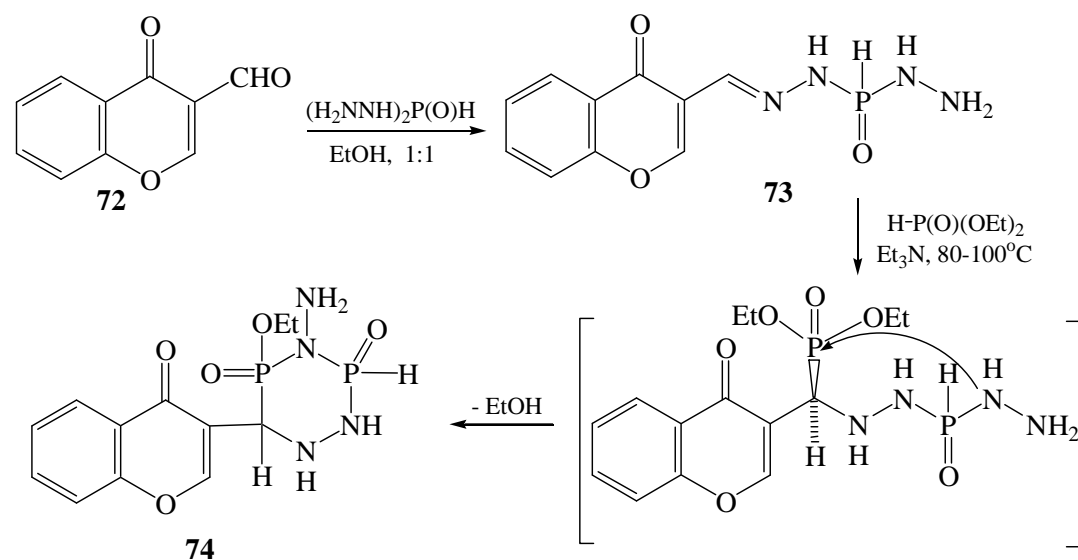

Scheme 19: Synthesis of 74

Pnickuk et $a l^{59}$, reported that the intramolecular heterocyclization of polysubstituted<smiles>[Y16]C=Nc1c(P([R12])([R12])=N)c(C)nn1[Al]</smiles>

75 pyrazole $\mathbf{7 5}$ afforded the fused phosphaheterobicyclic systems 76 via loss of dialkylamine.

\section{Functionally} triazaphospholopyridines (78) were obtained from $[1+4]$ cycloaddition of 1 -amino-2-imino- $2 \mathrm{H}$ -

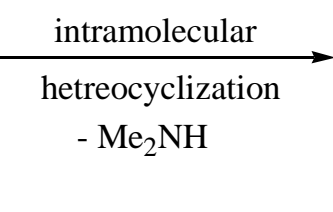

$1,2,4,3$

(1)

\footnotetext{
pyridine-3-carbonitrile (77) with $\mathrm{P}\left(\mathrm{NMe}_{2}\right)_{3}$ in refluxing benzene ${ }^{60}$.
}<smiles>[R]c1ccn(N)c(=N)c1C#N</smiles>

77<smiles>[R]c1ccn2npnc2c1C#N</smiles>

78 
In ${ }^{13}$ CNMR spectra these compounds absorb further downfield in the range $\delta$ 265-218.

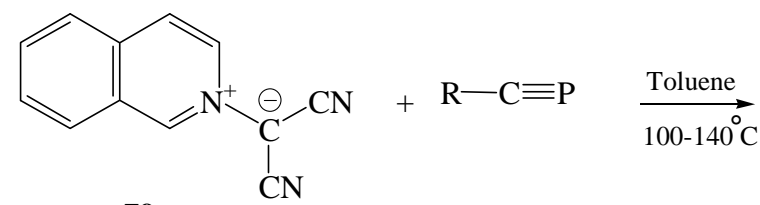

79

Under the same conditions, [3+2] cycloaddition of $\mathrm{N}$-cycloimmoni-um ylide $\mathbf{8 1}$ with phosphaalkyne (82) has been successfully<smiles>N#CC(C#N)[n+]1cc2ccccc2cn1</smiles>

employed to synthetic of 1,3,4-azaphospholo[1,2a]Phthalazine $(83)^{61}$.

Also, $\mathrm{N}$-isoquinolinium 79 reacts with $\mathrm{R}$ $\mathrm{C}$ P $\mathrm{P}$ in boiling toluene (glass pressure tube) ${ }^{61}$ to form the 1,3-azaphospholoquinoline derivatives $\mathbf{8 0}$<smiles>[R]C1=PC2c3ccccc3C=CN2C1C#N</smiles>

80<smiles></smiles>

On the other hand, 2,3- condense with $\mathrm{PCl}_{3} / \mathrm{Et}_{3} \mathrm{~N}$ led to the direct formation dialkylbenzothiazolium bromides (84) when of compound $85^{62}$.<smiles>[R]Cc1sc2ccccc2[n+]1C[R]</smiles>

84<smiles>CCN(C)CC(C)Br</smiles>

3-alkyl-2-

$\mathrm{Et}_{3} \mathrm{~N}$ yielded the 1,2,4-phosphazabenzthiazole $87^{63,64}$.<smiles>[R]C[n+]1c(N)sc2ccccc21</smiles>

86

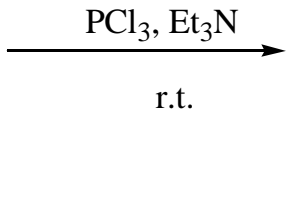


Most spectral study of organophosphorus heterocyclic compounds has been undertaken because of their wide applications in agriculture as pesticide and industry, The mass spectra of a series of 2-substituted-2,3-dihydro-1H-naphtho[1,8de] $(1,3,2)$-diazaphosphorine-2-oxides (88) were studied to establish their fragmentation processes. The major fragmentation patterns are the loss of aryloxy substituent and $\mathrm{RPO}_{2} \mathrm{H}$ moieties from the molecular ion. The fragmentation pattern is supported by meta stables, high resolution and collision activation dissociation data [Scheme $20 \mathrm{~A}]^{61 \mathrm{a}}$. Raju et $\mathrm{a} /{ }^{/ 1 \mathrm{~b}}$, reported the synthesis, electron impact and high resolution mass spectral of 2substituted-3-(4-methylphenyl)-naphth[1,2e] $(1,3,2)$ oxazaphosphorine-2-oxides/sulfide.

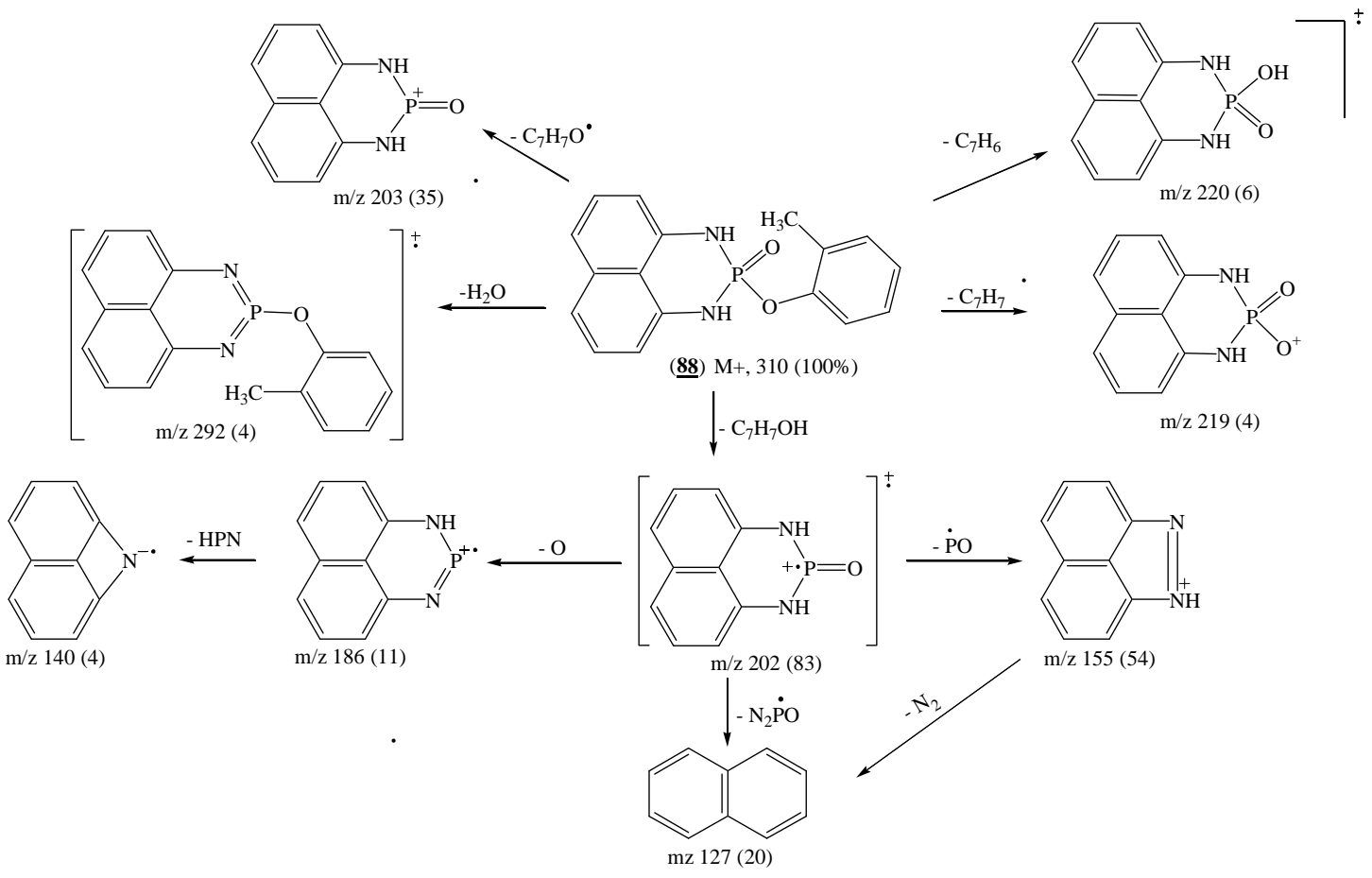

Scheme 20: Mass fragmentation of compound 88

\section{Spectrophotometric Determinations of Phosphorus}

Numbers of spectrophotometric methods for determination of phosphorus, based on the formation of heteropoly acid with molybdate have been described. The molar absorptivity of these heteropoly acids in the aqueous solution or in organic solvents after solvent extraction, are generally low ${ }^{61}$. Several cationic dyes, for example; methylene blue, ethyl violet, crystal violet, auramine, malachite green have been used for the determination of phosphorus ${ }^{62}$. The spectrophotometric determination of phosphates using above dyes processes have limited use due to several disadvantages. ${ }^{63}$

Recently, A novel curing agent of epoxy resins (EPO), bis(3-amino-2-thienyl) phenylphosphine oxide (ABTPPO), was synthesized and characterized. ABTPPO was used as a flame retardant curing agent, and used to prepare a novel halogen-free flame retardant EPO composite. ${ }^{64}$ In addition to a reported of a miniature flow-through detector methods useful for bimodal, photometric and fluorimetric, determination of phosphates ${ }^{65}$ and $A$ simple manifold flow injection analysis (FIA) for determining phosphorus in the presence of arsenate in water ${ }^{66}$ 


\section{CONCLUSION}

This review cover published literature concerning the synthetic of fused biheterocyclic nitrogen containing phosphorus atom over the period 1999-2014, updating our earlier review ${ }^{6}$ and on the area of bioactive 1,2,4-triazine derivatives ${ }^{11,12,40,67,68,69}$.

The developments in this area will help to persuade the important strategy to synthesis of phospha-heterocyclic nitrogen-five and sixmembered rings.

\section{REFERENCES}

1. M. Balali-Mood, M. Abdollahi (eds.), Basic and Clinical Toxicology of Organophosphorus Compounds, DOI 10.1007/978-1-4471-5625-3, SpringerVerlag London 2014, p 25-34.

2. Q. Dai, R. Chen; Phosphorus, Sulfur and Silicon 1997, 122, 261.

3. L. Nion, F. C. Ru-Yn Chen, J. A. Zhou, Phosphorus, Sulfur and Silicon 1997, 130, 65).

4. J. S. Tang, J. G. Verkade; U S Patent, 5260 436 1993; Chem. Abstr. 120, 218836v (1993).

5. A. K. Tiwari, B. K. Dubey, I. C. Shukla, J. Indian Chem. Soc. 80, 717 (2003).

6. I. C. Shukla, P. K. Dwived, J. Indian Chem. Soc. 82, 670 (2005).

7. T. E. Ali, R. M. Abdel-Rahman, F. I. Hanafy; Phosphorus, Sulfur and Silicon 183, 1-13 (2008).

8. A. E. Wroblewski, J. Pinkas, J. G. Verkade, Main Group Chem. 1, 69 (1995).

9. A. Naiini, V. G. Young, J. G. Verkade; Polyhedron, 16, 2087, (1997).

10. P. Mc Laughlin, J. G. Verkade; Organometallics, 17, 5937 (1998).

11. B. D. Sa, J. G. Verkade; J. Am. Chem. Soc., 118(12), 832 (1996).

12. R. M. Abdel-Rahman; Pharmazie, 56(1), 1822 (2001)

13. R. M. Abdel-Rahman; Pharmazie, 56(3), 195204 (2001).

14. R. M. Abdel-Rahman; Boll. Chim. Farmaceutico, 140,401 (2001).

15. Y. Xu, K. Yan, B. Song, G. Xu, S. Yang, W. Xue, D. Hu, P. Lu, L. Ouyang, Z. Chen; Molecule, 11, 6660 (2006).

16. L. Wan, I. Alkorta, J. Elguero, J. Sun, W. Zheng; Tetrahedron, 63, 9129 (2007).

17. F. W. Krock, F. Krohnke; Chem. Ber., 102, 659 (1969).
18. U. Bergstra, A. Hoffmann, M. Regitz; Tetrahedron Lett. 33, 1049 (1992).

19. R. H. Huisgen, J. Org. Chem., 41, 403 (1976).

20. R. K. Bansal, K. Karaghosoff, N. Gupta, A. Schmidpeter, C. Spindler, Chem. Br., 124, 475 (1991).

21. R. K. Bansal, N. Gupta, A. Surana; J. Indian Chem. Soc., 75, 648 (1998).

22. R. M. Abdel-Rahman; Trends Heterocycl. Chem., 8, 187 (2002).

23. R. K. Bansal, V. Kabra, N. Gupta, K. Karaghiosoff; J. Indian Chem. Soc., 31B, 254 (1992).

24. N. Gupta, C. B. Jain, J. Heinnicke, N. Bharatiya, R. K. Bansal, P. G. Jones; Heteroatom Chem., 9, 333 (1998).

25. R. K. Bansal, N. Gupta, R. Gupta, G. Pandey, M. Agarwal; Phosphorus, Sulfur and Silicon 112, 121 (1996).

26. R. K. Bansal, R. Mahnot, D. C. Sharma, K. Karaghiosoff, A. Schmidpeter; Heteroatom Chem.,3, 351 (1992).

27. G. Markl, S. Pflaum; Tetrahedron Lett. 28, 1511 (1987).

28. K. Karaghiosoff, R. K. BansI, N. Gupta; Z. Naturfosch. Teil B. 47, 373 (1992).

29. R. K. Bansal, G. Pandey, R. Gupta, K. Karaghiosoff, A. Schmidpeter; Synthesis, 173 (1995).

30. G. Markl, S. Pelaum, Tetrahedron Lett., 29, 3387 (1988).

31. R. K. Bansal, N. Gandhi, K. Karaghiosoff, A. Schmidpeter; Z. Naturforsch. Teil, 50, 558 (1995).

32. K. Karaghiosoff, A. Schmidpeter, P. Mayer "Synthetic Methods in Organometallic Chemistry”. G. Thieme, Stuttgart, 3, Group, (1995).

33. K. Karaghiosoff, C. Cleve, A. Schmidpeter; Phosphorus, Sulfur, 28, 289 (1986). 
34. I. A. Litvinov, K. Karaghiosoff, A. Schmidpeter, E. Y. Zabotina, E. N. Dianora; Heteroatom Chem., 2, 369 (1991).

35. E. C. Taylor, I. J. Turchi; Chem. Rev., 79, 2 (1979).

36. A. Schmidpeter, G. Jochem; Tetrahedron Lett., 33, 471 (1992).

37. P. Molina, M. Alajarin, A. Lopez-Lazaro; J. Chem. Soc., Perk. Trans. 1(12), 2037 (1986).

38. P. Molina, M. Alajarin, A. Lopez-Lazaro; Tetrahedron, 46(12), 4353 (1990).

39. Q. Dai, R. Chen; Phosphorus, Sulfur and Silicon 122, 261 (1997). *

40. J. Zhou, Y.Qui, K. Feng, R-Y. Chen; Synthetic Commn., 28(24), 4673 (1998).

41. R. M. Abdel-Rahman; Phosphorus, Sulfur and Silicon 166, 315 (2000).

42. P. Molina, M. Alajarin, A. Lopez-Lazaro; Tetrahedron, 47(33), 6747 (1991).

43. Y. O. El-Khoshnieh; Phosphorus, Sulfur and Silicon 139, 163 (2000).

44. Y.O.El-Khoshnieh, Y. A. Ibrahim; Phosphorus, 101, 67 (1995).

45. Z. El-Gendy, J. Morsy, H. Allimony, W. AbdelMomen, R. M. Abdel-Rahman Phosphorus, Sulfur and Silicon 178(9), 2055 (2003).

46. R. Lu, N. Yang, Z. Shang, Phosphorus, Sulfur and Silicon 108, 197 (1996).

47. M. R. Mohan, T. S. Hafez, M. M. Henary; Phosphorus, Sulfur and Silicon 139, 13 (1998).

48. T. B. Hwang, L. Feiliu, W.-Qian Yan, X.-Ming Yu, Xu.-Hong Qian, J.-L. Zkang; Phosphorus, Sulfur and Silicon 122, 299 (1997).

49. S. N. Tandura, M. G. Voronkov, N. V. Alekseer; Top. Curr. Chem., 131, 99 (1986).

50. M. A. H. Laramary, J. G. Verkade, Z. Anorg; Allg. Chem., 605, 163 (1991).

51. Y. A. Ibrahim, A. M. Kadry, M. R. Ibrahim, J. N. Lisgarten, B. S. Potfer, R. A. Palmer; Tetrahedron 55, 13457 (1999).

52. L. Nian He, R.-XI, Zhuo, X-Peng Liu, F. Caio, Phosphorus, Sulfur and Silicon 144, 453 (1999).

53. Y. Haribaba, M. A. Kumar, K. Srinivasulu, C. S. Reddy, C. N. Raju; Arkivoc, 189 (2006).

54. M. Maffei, G. Buono, Tetrahedron 59, 8821
(2003).

55. M. R. Bryce, R. S. Matthews; J. Organomet. Chem., 325, 153 (1997).

56. J. Hernadez, F. M. Gaycoalea, D.Z. Rivera, J. J. Onofre, K. Martinez, J. Lizardi; Tetrahedron, 62, 2520 (2006).

57. A. J. Cristu, J. L. Pirat, D. Birieux, J. Monbrum, C. Ciptadi. Y. A. Beko; J. Organomet. Chem., 690, 2472 (2005).

58. T. El-Sayed Ali; Arkivoc, ii, 71-79 (2008).

59. M. Maffei, G. Buono, Tetrahedron 59, 8821 (2003).

60. A. M. Pinhuk, A. S. Merkulov, G. V. Oshovsky, A. A. Tolmachas; Phosphorus, Sulfur and Silicon 144-146, 713 (1999).

61. a) C. Devendranath R., G. T. Reddy, C. N. Raju; Indian J. Heterocycl. Chem.., 4, April, 285 (1995). b. C. N. Raju, C. Das, G. S. Reddy; Indian J. Heterocycl. Chem., 4 April, 281 (1995).

62. C. Wodlin, M. G. Mollon; Anal. Chem., 25, 1168 (1953).

63. S. Motomizu, M. Oshima, A. Hirashima; Anal. Chim. Acta., 211, 119 (1988)

64. Xu M., Zhao W., Li B., Yang K. and Lin L. (2014), Synthesis of a phosphorus and sulfurcontaining aromatic diamine curing agent and its application in flame retarded epoxy resins, Fire and Materials. doi: 10.1002/ fam.2252

65. Marta Fiedoruk, Ellbieta Mieczkowska, Robert Koncki, Aukasz Tymecki. A bimodal optoelectronic flow-through detector for phosphate determination. Talanta, Volume 128, 1 October 2014, Pages 211-214

66. V. Gerez, K. Rondano, C. E. L. Pasquali. A simple manifold flow injection analysis for determining phosphorus in the presence of arsenate Journal of Water Chemistry and Technology, 2014, Volume: 36, Issue 1, 1924

67. S. Chakravarty, R. K. Mishra; J. Indian Chem. Soc., 71, 717 (1994)

68. R. M. Abdel-Rahman; Pharmazie, 54(11), 791 (1999)

69. R. M. Abdel-Rahman; Pharmazie, 56(4), 275 (2001). 